\title{
Game Theory on the Influence of Government Subsidy on the Industry-University-Research Cooperative Innovation
}

\author{
Mengyi Wang, Haihua Wang \\ School of Management, Shanghai University, Shanghai 200444, China \\ Corresponding author e-mail: wangmengyi0810@163.com
}

Keywords: Government subsidy, Industry-University-Research, cooperative innovation

\begin{abstract}
The government as a third party involved in the cooperative innovation among the Industry-University-Research Cooperation, and the government in the form of subsidies to coordinate corporate and research institutions R\&D investment and profit benefits. Based on the game theory perspective, this paper constructs a three-party game model of government, industry, university and research institutions, and discusses the optimal subsidy rate and policy of government in the three situations of cooperation: equilibrium of cooperative game, static game of complete information, dynamic game of complete and perfect information.
\end{abstract}

\section{Introduction}

Knowledge innovation is an important driving force for organizations to enhance their competitiveness and achieve sustainable development. [1] According to the "Resource Dependence Theory [2]", an organization cannot independently own all the technologies and capabilities in the innovation process. Therefore, in the face of diversified and decentralized knowledge resources, cross-organizational cooperation has become the main way to innovate.

Industry-university-research(IUR) cooperation innovation is a kind of cross-organization cooperation behavior. It regards university and research institutions who focus on the research as the subject of knowledge innovation and regards industry who applies research results into real products as the subject of technological innovation [3]. From the perspective of game theory, IUR cooperation innovation refers a platform of "non-zero-sum game" among industry, university and research institutions and government. And the game theory analysis is a process helping game players to make decision when government adjusted the R\&D investment subsidies which had an impact on the innovation performance of IUR.

This paper mainly discusses whether industry and university-research's R\&D investment will be affected by government subsidies as IUR is a special form of cross-organizational cooperative innovation from the perspective of the game theory. Also, this paper discusses what kind of game action will be made by industry, university-research and government in different position to maximize profits.

\section{Model Setup}

In the process of government subsidies affecting IUR cooperation innovation, a three-party game model can be established. Industry is the capital exporter $\left(\mathrm{P}_{\mathrm{i}}\right)$, university and research institutions $\left(\mathrm{P}_{\mathrm{ur}}\right)$ are the technology providers, and government $\left(\mathrm{P}_{\mathrm{g}}\right)$ is a third party. 
It is assumed a multi-stage game. Therefore, there are three positions: cooperative equilibrium game, complete information static game, and complete and perfect information dynamic game. The game strategy of industry, university and research institutions is investment in capital (K) and technology (L); the strategy of government is the percentage coefficient of subsidies. If the government's subsidy for industry is $\delta_{1}$, and for university and research institutions is $\delta_{2}$, then the total subsidy is $\delta_{1}+\delta_{2}$. With regard to game utility, the Cobb-Douglas production function is used to express innovations [4]:

$$
\mathrm{Q}=A K^{\alpha} \mathrm{L}^{\beta}
$$

$\mathrm{Q}$ is the cooperative innovation output; $\mathrm{A}$ is the coefficient; $\mathrm{K}$ and $\mathrm{L}$ are the investment of $\mathrm{P}_{\mathrm{i}}$ and $\mathrm{P}_{\mathrm{ur}} ; \alpha$ and $\beta$ are the influence factors of the investment of $P_{i}$ and $P_{u r}(\alpha+\beta \leqslant 1)$.

According to the basic principles of economics [5], the utility of $\mathrm{P}_{\mathrm{i}}$ and $\mathrm{P}_{\mathrm{ur}}$ can be obtained:

$$
\begin{aligned}
& \mathrm{U}_{1}=\mathrm{R}_{1} \mathrm{Q}-\mathrm{K}+\delta_{1} \mathrm{~K} \\
& \mathrm{U}_{2}=\mathrm{R}_{2} \mathrm{Q}-\mathrm{L}+\delta_{2} \mathrm{~L}
\end{aligned}
$$

Since the $\mathrm{P}_{\mathrm{g}}$ 's utility is difficult to measure directly in IUR cooperation innovation, this paper defines its utility as the difference between the utility of $\mathrm{P}_{\mathrm{i}} 、 \mathrm{P}_{\mathrm{ur}}$ and $\mathrm{P}_{\mathrm{g}}$ 's subsidies, then $\mathrm{P}_{\mathrm{g}}$ 's utility is:

$$
\mathrm{U}_{3}=\left(\mathrm{R}_{1}+\mathrm{R}_{2}\right) \mathrm{Q}-\mathrm{K}-\mathrm{L}
$$

\section{Game Playing Analysis}

\subsection{Cooperative equilibrium game}

This position means that industry, university and research institutions have formed the alliance. At this time, in the face of government subsidies, they are a whole, and they are seeking their own R\&D investment under the maximum of common utility.

The total utility of $\mathrm{P}_{\mathrm{i}}$ and $\mathrm{P}_{\mathrm{ur}}$ is the sum of the utility of them and is defined as $\mathrm{U}\left(\mathrm{U}_{1}+\mathrm{U}_{2}\right)$ :

$$
\mathrm{U}=\left(\mathrm{R}_{1}+\mathrm{R}_{2}\right) \mathrm{Q}-\left(1-\delta_{1}\right) \mathrm{K}-\left(1-\delta_{2}\right) \mathrm{L}=\mathrm{A}\left(\mathrm{R}_{1}+\mathrm{R}_{2}\right) \mathrm{K}^{\alpha} \mathrm{L}^{\beta}-\left(1-\delta_{1}\right) \mathrm{K}-\left(1-\delta_{2}\right) \mathrm{L}(5)
$$

Finding the partial derivatives of $\mathrm{K}$ and $\mathrm{L}$ of the above formula respectively and letting them be 0 , the formulas of $\mathrm{K}$ and $\mathrm{L}$ can be obtained:

$$
\begin{aligned}
& \mathrm{K}=\left[\mathrm{A}\left(\mathrm{R}_{1}+\mathrm{R}_{2}\right)\right]^{\frac{1}{1-\alpha}} * \frac{\alpha}{{ }^{1-\delta_{1}}}{ }^{\frac{1}{1-\alpha}} * \mathrm{~L}^{\frac{\beta}{1-\alpha}} \\
& \mathrm{L}=\left[\mathrm{A}\left(\mathrm{R}_{1}+\mathrm{R}_{2}\right)\right]^{\frac{1}{1-\beta}} *{\frac{\beta}{1-\delta_{2}}}^{\frac{1}{1-\beta}} * \mathrm{~K}^{\frac{\alpha}{1-\beta}}
\end{aligned}
$$

Substituting the above two formulas into $\mathrm{P}_{\mathrm{g}}$ utility $\mathrm{U}_{3}$, it can be obtained:

$$
\begin{gathered}
\mathrm{U}_{3}=\left[\mathrm{A}\left(\mathrm{R}_{1}+\mathrm{R}_{2}\right)\right]^{\frac{1}{1-\alpha-\beta}} *\left(\frac{\alpha}{1-\delta_{1}}\right)^{\frac{\alpha}{1-\alpha-\beta}} *\left(\frac{\beta}{1-\delta_{2}}\right)^{\frac{\beta}{1-\alpha-\beta}}-\left[\mathrm{A}\left(\mathrm{R}_{1}+\mathrm{R}_{2}\right)\right]^{\frac{1}{1-\alpha-\beta}} *\left(\frac{\alpha}{1-\delta_{1}}\right)^{\frac{1-\beta}{1-\alpha-\beta}} * \\
\left(\frac{\beta}{1-\delta_{2}}\right)^{\frac{\beta}{1-\alpha-\beta}}-\left[\mathrm{A}\left(\mathrm{R}_{1}+\mathrm{R}_{2}\right)\right]^{\frac{1}{1-\alpha-\beta}} *\left(\frac{\alpha}{1-\delta_{1}}\right)^{\frac{\alpha}{1-\alpha-\beta}} *\left(\frac{\beta}{1-\delta_{2}}\right)^{\frac{1-\beta}{1-\alpha-\beta}}
\end{gathered}
$$

The proportion of subsidies when maximizing $\mathrm{P}_{\mathrm{g}}$ utility is guided by the partial derivatives of $\delta_{1}$ and $\delta_{2}$, and their partiality is 0 :

Substituting it into the formulas of $\mathrm{K}$ and $\mathrm{L}$ :

$$
\delta_{1}^{*}=\delta_{2}^{*}=0
$$

$$
\begin{aligned}
& \mathrm{K}=\left[\mathrm{A}\left(\mathrm{R}_{1}+\mathrm{R}_{2}\right)\right]^{\frac{1}{1-\alpha-\beta}} * \alpha^{\frac{1-\beta}{1-\alpha-\beta}} * \beta^{\frac{\beta}{1-\alpha-\beta}} \\
& \mathrm{L}=\left[\mathrm{A}\left(\mathrm{R}_{1}+\mathrm{R}_{2}\right)\right]^{\frac{1}{1-\alpha-\beta}} * \alpha^{\frac{\alpha}{1-\alpha-\beta}} * \beta^{\frac{1-\alpha}{1-\alpha-\beta}}
\end{aligned}
$$

Therefore, in the position of the cooperative equilibrium game, the best strategy for $\mathrm{P}_{\mathrm{g}}$ subsidies is 0 , and the $R \& D$ investment of $P_{i}$ and $P_{u r}$ depends on its influence factors. Because $P_{i}$ and $P_{u r}$ form the alliance in advance, no matter how the $\mathrm{P}_{\mathrm{g}}$ subsidies, they will choose $\mathrm{R} \& \mathrm{D}$ investment that can maximize their mutual benefits. That is, $\mathrm{P}_{\mathrm{g}}$ subsidies will not have an impact. 


\subsection{Non-cooperative complete information static game}

This position means that industry, university and research institutions have not formed an alliance. The government decides the subsidy ratio coefficient, and industry, university and research institutions make decisions on their $R \& D$ investments at the same time when the government subsidy allocation is known to maximize their own interests. The government's subsidy coefficients $\delta_{1}$ and $\delta_{2}$ are given known.

According to the $\mathrm{U}_{1}$ and $\mathrm{U}_{2}$, the inputs of $\mathrm{P}_{\mathrm{i}}$ and $\mathrm{P}_{\mathrm{ur}}$ can be obtained when maximizing their utility:

$$
\begin{aligned}
& \mathrm{K}=\mathrm{A}^{\frac{1}{1-\alpha}} * \frac{\alpha \mathrm{R}_{1}}{1-\delta_{1}} \frac{1}{1-\alpha} * \mathrm{~L}^{\frac{\beta}{1-\alpha}} \\
& \mathrm{L}=\mathrm{A}^{\frac{1}{1-\beta}} * \frac{\beta \mathrm{R}_{2}}{1-\delta_{2}} \frac{1}{1-\beta} * \mathrm{~K}^{\frac{\alpha}{1-\beta}}
\end{aligned}
$$

Then, the $\mathrm{P}_{\mathrm{g}}$ utility can be obtained:

$$
\begin{gathered}
\mathrm{U}_{3}=\left(\mathrm{R}_{1}+\mathrm{R}_{2}\right) \mathrm{A}^{\frac{1}{1-\alpha-\beta}} * \frac{\alpha \mathrm{R}_{1} \frac{\alpha}{1-\delta_{1}}}{1-\alpha-\beta} * \frac{\beta \mathrm{R}_{2}}{1-\delta_{2}} \frac{\beta}{1-\alpha-\beta} \\
-\mathrm{A}^{\frac{1}{1-\alpha-\beta}} * \frac{\alpha \mathrm{R}_{1}}{\frac{1-\beta}{1-\alpha-\beta}} * \frac{\beta \mathrm{R}_{2}}{1-\delta_{1}} \frac{\beta}{1-\alpha-\beta}-\mathrm{A}^{\frac{1}{1-\alpha-\beta}} * \frac{\alpha \mathrm{R}_{1}}{1-\delta_{1}} \frac{\alpha}{1-\alpha-\beta} * \frac{\beta \mathrm{R}_{2}}{{ }^{1-\alpha-\beta}}
\end{gathered}
$$

The best subsidies when maximizing $\mathrm{P}_{\mathrm{g}}$ utility is:

$$
\begin{aligned}
& \delta_{1}^{*}=\frac{\mathrm{R}_{2}}{\mathrm{R}_{1}+\mathrm{R}_{2}} \\
& \delta_{2}^{*}=\frac{\mathrm{R}_{1}}{\mathrm{R}_{1}+\mathrm{R}_{2}}
\end{aligned}
$$

Substituting the formulas of $\mathrm{K}$ and $\mathrm{L}$ into $\mathrm{K}^{*}$ and $\mathrm{L}^{*}$ and finding partial guides for $\delta_{1}$ and $\delta_{2}$ :

$$
\frac{\partial \mathrm{K}^{*}}{\partial \delta_{1}}>0 ; \frac{\partial \mathrm{K}^{*}}{\partial \delta_{2}}>0 ; \frac{\partial \mathrm{L}^{*}}{\partial \delta_{1}}>0 ; \frac{\partial \mathrm{L}^{*}}{\partial \delta_{2}}>0 ;
$$

Substituting the formulas of $\mathrm{K}$ and $\mathrm{L}$ into $\mathrm{U}_{1}$ and $\mathrm{U}_{2}$ and finding partial guides for $\delta_{1}$ and $\delta_{2}$ :

$$
\frac{\partial \mathrm{U}_{1}}{\partial \delta_{1}}>0 ; \frac{\partial \mathrm{U}_{1}}{\partial \delta_{2}}>0 ; \frac{\partial \mathrm{U}_{2}}{\partial \delta_{1}}>0 ; \frac{\partial \mathrm{U}_{2}}{\partial \delta_{2}}>0 ;
$$

Therefore, in the position of non-cooperative complete information static games, the best strategy for $\mathrm{P}_{\mathrm{g}}$ subsidies will be affected by the marginal profit rate of the other party. Because when $\mathrm{P}_{\mathrm{i}}$ and $\mathrm{P}_{\text {ur }}$ do not form an alliance in advance, the $\mathrm{P}_{\mathrm{g}}$ always gives a higher subsidy rate to the party with a lower marginal profit. So the players will reduce their own marginal revenue to exchange a higher subsidy rate. In this position, $\mathrm{P}_{\mathrm{g}}$ subsidies play a balanced role between the $\mathrm{P}_{\mathrm{i}}$ and $\mathrm{P}_{\mathrm{ur}}$.

At the same time, by comparing the actual investment, utility and $\mathrm{P}_{\mathrm{g}}$ subsidy rates, it can be assumed that the innovation investment and utility of $\mathrm{P}_{\mathrm{i}}$ and $\mathrm{P}_{u r}$ will increase as the $\mathrm{P}_{\mathrm{g}}$ subsidy rate increases. Because the $\mathrm{P}_{\mathrm{g}}$ subsidies play an incentive role in the IUR cooperative innovation. When there are more $\mathrm{P}_{\mathrm{g}}$ subsidies, the utility are also higher, and no one will give up the higher profits.

\subsection{Non-cooperative complete and perfect information dynamic game}

This position means that industry and university and research institutions have not formed an alliance, and one of them plays a leading role. The government decides the subsidy ratio coefficient, and then industry and university and research institutions make decisions on their R\&D investments when the government subsidy allocation is known. One of them (for example, the industry) can first decide R\&D investment that can maximize its interests, and the other one (university and research institutions) determines the R\&D investment that maximizes its interests while another party's investment is known. The government's subsidy coefficients $\delta_{1}$ and $\delta_{2}$ are the given known numbers.

Firstly, $\mathrm{P}_{\mathrm{i}}$ determines the investment that can maximize its interests:

$$
\mathrm{K}=\left(\frac{1-\delta_{1}}{\alpha \mathrm{R}_{1} \mathrm{~A}}\right)^{\frac{1}{\alpha-1}} * \mathrm{~L}^{\frac{\beta}{1-\alpha}}
$$


Secondly, $\mathrm{P}_{\mathrm{ur}}$ determine the investment according to the investment of $\mathrm{P}_{\mathrm{i}}$, then $\mathrm{K}$ and $\mathrm{L}$ can be obtained:

$$
\begin{aligned}
& \mathrm{K}=\mathrm{A}^{\frac{1}{1-\alpha-\beta}} *(1-\alpha)^{\frac{\beta}{\alpha+\beta-1}} *\left(\frac{\alpha \mathrm{R}_{1}}{1-\delta_{1}}\right)^{\frac{1-\beta}{1-\alpha-\beta}} *\left(\frac{\beta \mathrm{R}_{2}}{1-\delta_{2}}\right)^{\frac{\beta}{1-\alpha-\beta}} \\
& \mathrm{L}=\mathrm{A}^{\frac{1}{1-\alpha-\beta}} *(1-\alpha)^{\frac{1-\alpha}{\alpha+\beta-1}} *\left(\frac{\alpha \mathrm{R}_{1}}{1-\delta_{1}}\right)^{\frac{\alpha}{1-\alpha-\beta}} *\left(\frac{\beta \mathrm{R}_{2}}{1-\delta_{2}}\right)^{\frac{1-\alpha}{1-\alpha-\beta}}
\end{aligned}
$$

Substituting the above two formulas into $\mathrm{P}_{\mathrm{g}}$ utility, $\mathrm{U}_{3}$ can be obtained:

$$
\begin{aligned}
& \mathrm{U}_{3}=\left(\mathrm{R}_{1}+\mathrm{R}_{2}\right) \mathrm{A}^{\frac{1}{1-\alpha-\beta}} *(1-\alpha)^{\frac{\beta}{\alpha+\beta-1}} *\left(\frac{\alpha \mathrm{R}_{1}}{1-\delta_{1}}\right)^{\frac{\alpha}{1-\alpha-\beta}} *\left(\frac{\beta \mathrm{R}_{2}}{1-\delta_{2}}\right)^{\frac{\beta}{1-\alpha-\beta}}-\mathrm{A}^{\frac{1}{1-\alpha-\beta}} *(1-\alpha)^{\frac{\beta}{\alpha+\beta-1}} *\left(\frac{\alpha \mathrm{R}_{1}}{1-\delta_{1}}\right)^{\frac{1-\beta}{1-\alpha-\beta}} * \\
& \left(\frac{\beta \mathrm{R}_{2}}{1-\delta_{2}}\right)^{\frac{\beta}{1-\alpha-\beta}}-\mathrm{A}^{\frac{1}{1-\alpha-\beta}} *(1-\alpha)^{\frac{1-\alpha}{\alpha+\beta-1}} *\left(\frac{\alpha \mathrm{R}_{1}}{1-\delta_{1}}\right)^{\frac{\alpha}{1-\alpha-\beta}} *\left(\frac{\beta \mathrm{R}_{2}}{1-\delta_{2}}\right)^{\frac{1-\alpha}{1-\alpha-\beta}}
\end{aligned}
$$

The best subsidies when maximizing $\mathrm{P}_{\mathrm{g}}$ utility is:

Finding the case where $\delta_{2}{ }^{*}$ is 0 , that is:

$$
\begin{gathered}
\delta_{1}^{*}=\frac{\mathrm{R}_{1}}{\left(\mathrm{R}_{1}+\mathrm{R}_{2}\right)} \\
\delta_{2}^{*}=1-\frac{\mathrm{R}_{1}}{(1-\beta)\left(\mathrm{R}_{1}+\mathrm{R}_{2}\right)}
\end{gathered}
$$

$$
\frac{\mathrm{R}_{1}}{\mathrm{R}_{2}}=\frac{1-\beta}{\beta}, \delta_{2}^{*}=0 ; \frac{\mathrm{R}_{1}}{\mathrm{R}_{2}}>\frac{1-\beta}{\beta}, \delta_{2}^{*}<0 ; \frac{\mathrm{R}_{1}}{\mathrm{R}_{2}}<\frac{1-\beta}{\beta}, \delta_{2}^{*}>0 ;
$$

Assuming that the actual $R \& D$ investment of $\mathrm{P}_{\mathrm{i}}$ and $\mathrm{P}_{\mathrm{ur}}$ is $\mathrm{K}^{*}$ and $\mathrm{L}^{*}$, and then:

$$
\begin{aligned}
& \mathrm{K}^{*}=\mathrm{K}\left(1-\delta_{1}\right) \\
& \mathrm{L}^{*}=\mathrm{L}\left(1-\delta_{2}\right)
\end{aligned}
$$

Substituting the formulas of $\mathrm{K}$ and $\mathrm{L}$ into $\mathrm{K}^{*}$ and $\mathrm{L}^{*}$ and finding partial guides for $\delta_{1}$ and $\delta_{2}$ :

$$
\frac{\partial \mathrm{K}^{*}}{\partial \delta_{1}}>0 ; \frac{\partial \mathrm{K}^{*}}{\partial \delta_{2}}>0 ; \frac{\partial \mathrm{L}^{*}}{\partial \delta_{1}}>0 ; \frac{\partial \mathrm{L}^{*}}{\partial \delta_{2}}>0 ;
$$

Substituting the formulas of $\mathrm{K}$ and $\mathrm{L}$ into $\mathrm{U}_{1}$ and $\mathrm{U}_{2}$ and finding partial guides for $\delta_{1}$ and $\delta_{2}$ :

$$
\frac{\partial \mathrm{U}_{1}}{\partial \delta_{1}}>0 ; \frac{\partial \mathrm{U}_{1}}{\partial \delta_{2}}>0 ; \frac{\partial \mathrm{U}_{2}}{\partial \delta_{1}}>0 ; \frac{\partial \mathrm{U}_{2}}{\partial \delta_{2}}>0 ;
$$

Therefore, in the position of a non-cooperative and perfect information dynamic game, the best strategy for $\mathrm{P}_{\mathrm{g}}$ subsidies will be affected by the marginal profit rate of $\mathrm{P}_{\mathrm{i}}$ and the influence factors of $\mathrm{P}_{\mathrm{ur}}$. Because when $\mathrm{P}_{\mathrm{i}}$ and $\mathrm{P}_{\mathrm{ur}}$ do not form an alliance in advance, the marginal rate of return of the dominant party will adversely affect the $\mathrm{P}_{\mathrm{g}}$ 's subsidy to it, that is, if the marginal rate of return of the dominant party is high, the $\mathrm{P}_{\mathrm{g}}$ will suppress the innovation input of the dominant party through low subsidies or even no subsidies to encourage the other party to invest more. In this position, $\mathrm{P}_{\mathrm{g}}$ subsidies play a decisive role to curb the leverage of the dominant party between the $\mathrm{P}_{\mathrm{i}}$ and $\mathrm{P}_{\mathrm{ur}}$.

At the same time, by comparing the actual investment, utility and government subsidy rates, we can gain the same conclusions and explanations as complete information static game. That is to say, the innovation investment and utility of $\mathrm{P}_{\mathrm{i}}$ and $\mathrm{P}_{\mathrm{ur}}$ will increase with the $\mathrm{P}_{\mathrm{g}}$ subsidy rate increasing.

\section{Conclusion and suggestion}

Through the analysis of three positions of game: cooperative equilibrium game, complete information static game and complete and perfect information dynamic game, the government subsidy rate, subsidy policy and subsidy effect are summarized as follows: 
Table 1. Three position comparing.

\begin{tabular}{|c|c|c|c|}
\hline & $\begin{array}{c}\text { Cooperative } \\
\text { equilibrium game }\end{array}$ & $\begin{array}{c}\text { Complete } \\
\text { information static game }\end{array}$ & $\begin{array}{c}\text { Complete and perfect information } \\
\text { dynamic game }\end{array}$ \\
\hline $\begin{array}{l}\text { Subsidy } \\
\text { Rate }\end{array}$ & $\delta_{1}^{*}=\delta_{2}^{*}=0$ & $\begin{aligned} \delta_{1}^{*} & =\frac{R_{2}}{R_{1}+R_{2}} \\
\delta_{2}^{*} & =\frac{R_{1}}{R_{1}+R_{2}}\end{aligned}$ & $\begin{array}{c}\delta_{1}^{*}=\frac{R_{1}}{\left(R_{1}+R_{2}\right)} \\
\delta_{2}^{*}=1-\frac{R_{1}}{(1-\beta)\left(R_{1}+R_{2}\right)}\end{array}$ \\
\hline $\begin{array}{l}\text { Subsidy } \\
\text { Policy }\end{array}$ & No subsidies & $\begin{array}{l}\text { Give a higher rate of subsidy to } \\
\text { the party with a lower marginal } \\
\text { return; a lower rate of subsidy to } \\
\text { the party with a higher marginal } \\
\text { return }\end{array}$ & $\begin{array}{l}\text { Give the dominant party low } \\
\text { subsidies or even no subsidies; } \\
\text { give the other party high subsidies }\end{array}$ \\
\hline $\begin{array}{l}\text { Subsidy } \\
\text { Effect }\end{array}$ & No effect & $\begin{array}{l}\text { Balance the seesaw of the two } \\
\text { party }\end{array}$ & $\begin{array}{l}\text { Curb the leverage of the dominant } \\
\text { party }\end{array}$ \\
\hline
\end{tabular}

Based on the above results, this paper draws the following conclusions:

(1) The government subsidy plays an important role in IUR cooperation innovation. The government subsidy will, to a certain extent, affect the capital resources, human resources, and knowledge resources of IUR cooperation innovation. It will then affect the R\&D investment, revenue share, and distribution of profits of industry and university and research institution. The research conclusions of this paper demonstrate the effect of government subsidy on R\&D investment and revenue output.

(2) Government subsidies play an influential role in the innovation investment and R\&D investment of industry and university and research institutions. In general, whether there is a cooperation alliance, when government is involved, both parties' investment will be reduced with the government subsidy rate increasing. To gain more profit, they will invest more. From the perspective of the internal distribution of subsidies, when the cooperative alliance of industry and university and research institutions is formed, the government subsidies will have less impact on the investment of both parties, because at this time regardless of the model of government subsidies and the number of subsidies, both parties will decide their investment by maximizing their common interests, and investment won't be affected by the government subsidy rate, which means government subsidies in this position is a kind of "superfluous" behaviour that has no use. On the contrary, when the industry and university and research institutions do not form a cooperative alliance, the government subsidies have a greater impact on the investment of the two parties, in other words, they will adjust their R\&D investment according to the government subsidy rate so as to obtain the maximum benefit.

(3) The government subsidy can promote the innovation utility of industry and university and research institutions. The innovative utility of industry and university and research institutions will increase with the intervention of government subsidies and the increase of government subsidy rate. This is because when there are government subsidies, industry and university and research institutions will increase R\&D investment for profitability, in this way, the innovative utility will also rise correspondingly.

(4) The government subsidy policy and its role depend on the actual IUR cooperative innovation situation. If the government wants to promote the utility, it needs to adopt different subsidy rates and strategies in the different cooperation models to achieve different effects. When industry and university and research institutions form a cooperative alliance, because government subsidies play a minor role, the government subsidy rate can be appropriately reduced. When industry and university and research institutions do not form cooperative alliances and are equal partnerships, the government subsidy rate can be tilted to give high subsidies to the party with low marginal profits so as to balance the utility of both parties. When the industry and university and research institutions do not form a cooperative alliance and they are partners in which the dominant ones occupy the advantage, the government subsidy rate is giving disadvantaged parties high subsidy to suppress the dominant one, and avoiding the situation where the 
resource capability unbalanced, caused by over-investment.

The government's involvement in IUR cooperation innovation is the development trend of technological innovation in recent years. Industry and university and research institutions work together to carry out superior resources sharing innovation to achieve profitability. The government should suit the methods to the situation, improve innovation incentive policy, and give full play to the role of guidance and supervision with appropriate government actions to achieve a coordinated development of government, industry, university and research institutions.

\section{Acknowledgments}

This work was supported by the Ministry of education on the key projects of philosophy and Social Sciences (No:15JZD017)、National Natural Science Foundation of China (No:71373158) and the Youth Project of National Social Science Fund of China (No:13CGL014).

\section{References}

[1] Drucker P F. Post-capitalist society. Boston: Harvard Business School Pres. (1994)

[2] Pfeffer,J., and Salancik, G., The External Control of Organizations: A Resource Dependence Perspective, New York: Harper and Row. (1978)

[3] WANG ruixin, Li linjuan. Research on the Theoretical Framework of Collaborative Innovation. Scientific Management Research, 35(2017):17-21.

[4] JIANG minhui, JIA xiaohui. The Mechanism on Industrial Clusters' Impact on Regional Innovation Capacity Based on CD Production Function: An Empirical Study. China Soft Science, 06 (2013) 154-161+183.

[5] N. Gregory Mankiw, Principles of Economics. Cengage Learning. (2011) 